\title{
O Povo Não Assiste a Tudo Bestializado ${ }^{1}$
}

Antonio Lassance ${ }^{2}$

\section{PODER DA MÍDIA, EM TESE}

O objetivo deste artigo é investigar, a partir dos dados de entrevistas da pesquisa Radiografia do Brasil Contemporâneo, as atitudes dos brasileiros diante da mídia, em especial da mídia corporativa mais tradicional. Pergunta-se em que medida as pessoas assumem - se é que assumem - atitudes com base, sobretudo, nas informaçóes que obtêm da mídia. ${ }^{3}$ Dito de forma invertida, questiona-se até que ponto pessoas que podem ser distinguidas socialmente como ralé, batalhadoras e classe média reagem ou não criticamente aos conteúdos apresentados pela mídia e percebem as intençóes e os interesses que orientam o enquadramento da informação. ${ }^{4}$

A discussão incide sobre um debate teórico crucial e recorrente. Desde as primeiras pesquisas em comunicação até as mais atuais, que enfocam os efeitos das mídias sociais sobre o comportamento coletivo, pergunta-se até que ponto a mídia contribui mais para orientar, informar e formar cidadãos ou para produzir atitudes de "efeito manada", de caráter passional, e não racional ou, no mínimo, para esvaziar e desmobilizar posturas mais reflexivas e questionadoras ao status quo.

Um enquadramento recente desse debate é dado por Souza (2017). Em seu esquema argumentativo, o autor explica que os consumidores de informação tomam contato com as notícias por meio dos grandes grupos de comunicação, principalmente o Grupo Globo. Diante deles, permanecem "bestializados", prostrados e completamente indefesos, alvo fácil da indução que esses veículos fazem para que assumam opinióes e atitudes que contrariam seus próprios interesses.

Combinando-se a falta de pluralidade de informaçôes com a privatização cartelizada da esfera pública, a mídia seria capaz de cevar o conservadorismo na sociedade brasileira sem sofrer maiores contrapontos em sua narrativa. Souza (2017) ainda aponta que o processo de manipulação midiática para ser completo precisa que os veículos se apresentem como neutros, isentos de outros interesses que náo o de prestar um serviço de informação ao cidadão. Em suma, são essas as teses em questão que serão confrontadas com os dados extraídos do projeto Radiografia.

\section{ITINERÁRIO METODOLÓGICO}

A partir dos questionários aplicados pelo projeto Radiografia do Brasil Contemporâneo, o imenso corpo de dados textuais coligidos das entrevistas foi submetido a um processo de filtragem por meio do software Atlas.ti. A mineraçáo de dados usou como palavras-chave mídia e imprensa, que estavam

1. DOI: http://dx.doi.org/10.38116/bapi23art6

2. Técnico de planejamento e pesquisa na Diretoria de Estudos e Políticas do Estado, das Instituições e da Democracia (Diest) do Ipea.

3. Conceitua-se aqui o termo mídia como o conjunto dos meios de comunicação especificamente voltados a produzir e transmitir conteúdos, sejam eles de caráter informativo, publicitário ou de entretenimento - televisão, rádio, impressos (jornais e revistas vendidos em banca ou enviados a assinantes), cinema, outdoors e luminosos e internet. Quando se usa o termo meios de comunicação está se referindo a um universo mais abrangente, que inclui desde o telefone e os aparelhos de comunicação por transmissão de rádio às cartas. Na pesquisa do projeto Radiografia do Brasil Contemporâneo, foi perguntado especificamente aos entrevistados sobre os meios de consumo de informação, quais sejam, TV, rádio, impressos e internet. Convenciona-se usar a expressão corrente a mídia, no singular, para expressar esse conjunto de meios, ressaltando o caráter bastante diverso de cada uma delas.

4. A conceituação de ralé, batalhadores e classe média segue as definições de Souza (2017). 
presentes nas perguntas que foram submetidas aos entrevistados. Dessa mineração, então, surgiram as percepções sobre a mídia. ${ }^{5}$

Este artigo busca responder se as pessoas reagem ou não criticamente ao que recebem da mídia, supondo parcialidades e interesses. Para comparar os dados qualitativos do projeto Radiografia com informações quantitativas sobre mídia e consumo de informaçôes, foram utilizados os dados presentes em três ediçóes da Pesquisa Brasileira de Mídia, que afere hábitos de consumo de informação dos brasileiros (Brasil, 2014; 2015; 2016). Ao longo do artigo, foram reproduzidas falas de entrevistados que sejam elucidativas de raciocínios conexos - não necessariamente de comportamentos típicos ou homogêneos.

\section{COMO OS BRASILEIROS VEEM E REAGEM À MÍDIA?}

\subsection{A ralé e a mídia}

A pesquisa revela uma importância significativa dos maiores conglomerados de comunicação e da mídia televisiva nos hábitos de consumo de informação dos brasileiros. Ao mesmo tempo, evidencia-se um avanço acelerado da internet e a drástica redução do consumo do rádio e dos jornais e revistas impressos. Em linhas gerais, esses dados coincidem com os de pesquisas sobre hábitos de consumo da informação, conforme o gráfico $1 .^{6}$

\section{GRÁFICO 1}

\section{Brasil: hábitos de consumo de informação} (Em \%)

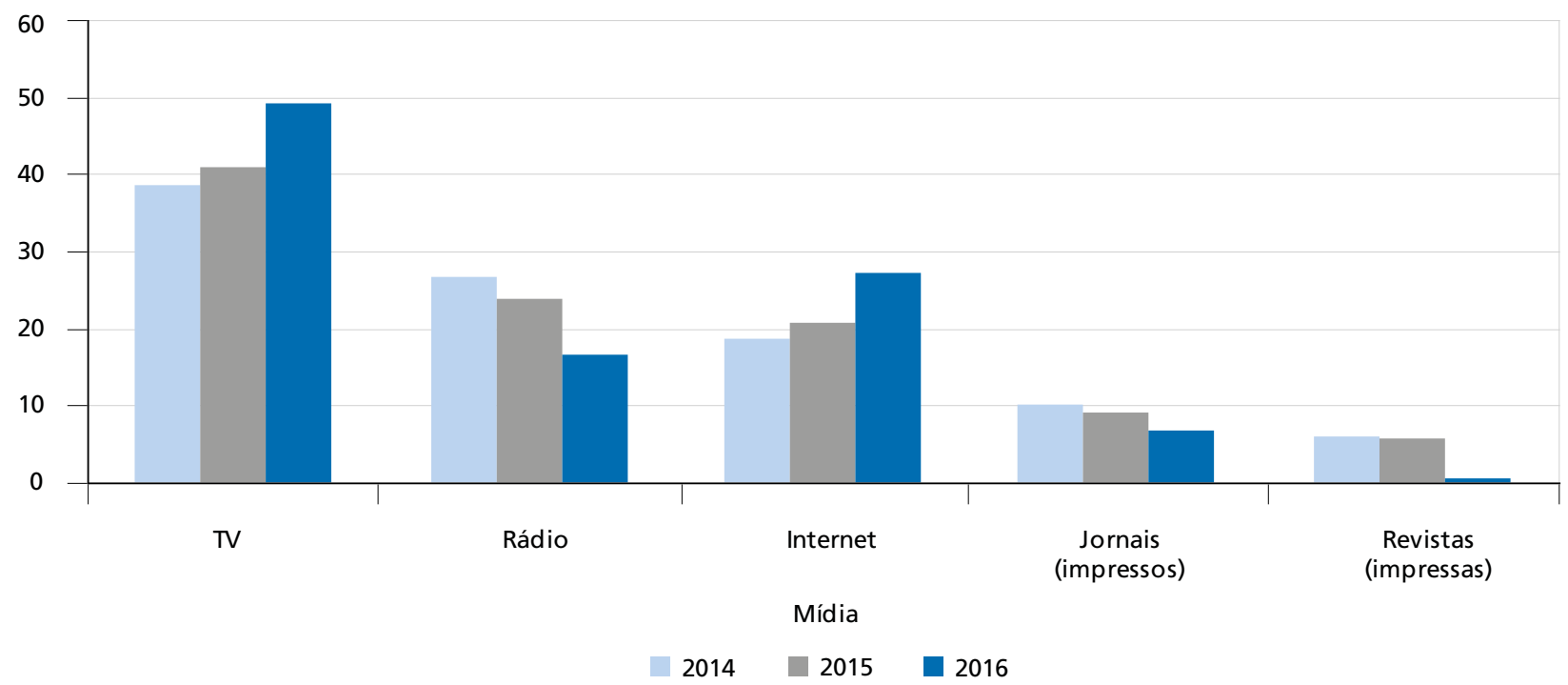

Fonte: Brasil (2014; 2015; 2016).

5. As entrevistas estão todas protegidas pela condição de anonimato, sendo por isso apenas assinaladas pelo número do entrevistado. 6. 0 gráfico mostra justamente a predominância do meio TV, o crescimento da internet e o declínio do rádio, jornais e principalmente das revistas impressas. É importante ressaltar que as pesquisas citadas ainda captam o crescimento da TV a cabo, até 2016, mas não seu declínio acelerado e recente diante dos serviços de streaming. Ressalte-se que esse declínio não necessariamente se reflete em um recuo muito grande das assinaturas de TV a cabo, tendo em vista que a contratação de internet banda larga ainda se dá, preferencialmente, por pacotes que incluem TV a cabo e telefone fixo. 
O consumo de informações é crescente conforme a renda. Assim, a ralé é quem menos comenta a influência da mídia. A TV aberta é a mídia a que essa classe mais tem acesso, dada a óbvia dificuldade de se adquirir informação e entretenimento pagos. O entrevistado 104108 afirma que seu consumo se restringe "à televisão mesmo. Jornal na TV. E, às vezes, de vez em quando, eu assisto a essas coisas da internet, com minhas colegas lá no trabalho. Aí vejo notícias, esse tipo de coisa” ${ }^{7}$

O ambiente familiar, o trabalho, a escola e a igreja são os principais espaços de socialização para a ralé, de onde lhe chega a informação, já processada. Embora as entrevistas não possam oferecer indicações estatísticas do fenômeno, é uma cogitação plausível, a ser aferida em outros estudos, que a ralé delegue a esses espaços e às pessoas com as quais tenha relações de maior confiança um filtro informativo que orienta suas conclusões sobre política e políticas públicas. $\mathrm{O}$ indicativo é que não apenas a renda e o tempo sejam fatores restritivos à ralé, mas também que a rede de confiança pessoal fale mais alto que a mídia.

Portanto, entre a ralé, não há indícios de que a narrativa midiática tenha como efeito direto, líquido e certo a própria "bestialização".

\subsection{Os batalhadores e a mídia}

Os batalhadores têm maior exposição à mídia, mas demonstram uma relação bastante pragmática e seletiva. Também se evidencia uma presença ainda grande da TV, mas com um avanço significativo da internet em seus hábitos de consumo, o que não ocorre com a ralé.

Ainda assim, o consumo de informação não se mostra acrítico, bestializado. Ao contrário, há sensações de desconfiança e mal-estar com a mídia. Os batalhadores escolhem seus programas preferidos, aqueles que estejam adequados, antes de mais nada, às suas rotinas diárias de trabalho e afazeres domésticos, e rejeitam outros, com base na percepção de que estariam consumindo seu tempo de forma inútil.

A título de exemplo, a entrevistada 102107 conta que se informa sobretudo pela TV, mas

só durante a semana, de noite, que eu vejo (...) Jornal nem tô assistindo, eles falam de política demais, e eu não tenho paciência. Essa coisa de Lava Jato, essa palhaçada... Tô cansada de ser enganada... Todo o dia, a mesma coisa... Internet, [só] de vez em quando, (...) entro naquele face e vejo lá na roça, tem um negócio que passa só coisa da roça.

O entrevistado 104117 revela que sua fonte exclusiva de informações é um único telejornal e, ainda assim, "acompanho enquanto tô fazendo hambúrguer."

A pesquisa já capta o avanço do consumo da internet e o desaparecimento quase total da mídia jornal impresso entre batalhadores. Diz a entrevistada 102120: “o que eu não olho, praticamente, é jornal, jornal de papel."

A entrevistada 110105 revela hábitos de consumo da informação ainda mais relacionados à internet: “não, na TV, não. Nem leio, nem vejo. É na internet. Jornal, geralmente, é muito raro, só quando eu tô comendo alguma coisa e a TV tá ligada”.

Entre batalhadores aparece a percepção de que o mundo da informação é cada vez mais "movediço", exigindo cautela com as informaçôes, pois não há filtro seguro proporcionado pelas próprias mídias.

A desconfiança com a mídia TV é recorrente entre os batalhadores. O mesmo entrevistado 103102 garante: "dependendo da informação, a que eu menos confio é na mídia, acredita? O jornalismo, eu

7. As entrevistas estão transcritas conforme a degravação natural das falas, sem modificação de eventuais incorreções gramaticais. 
acho muito comprado, (...) [os] ideais do jornalismo, porque ele sabe da verdade, e às vezes não passa a verdade." A entrevistada 103125, por sua vez, afirma: “a TV é muito manipuladora (...) programa de TV, por exemplo, o Jornal Nacional já deixei de assistir, porque eu não acredito muito na Globo, acredito que ela manipula. Eu assisto pouquíssimos programas de TV."

A tese da manipulação, portanto, encontra eco na percepção de batalhadores, mas isso não tem como efeito automático a bestialização desse público, e sim sua contestação ao conteúdo e o confronto com outras fontes de informações.

O entrevistado 118117 diz: “a gente sempre faz avaliaçóes, (...) ver o que é ou não confiável. O jornalismo hoje em dia tá deixando de ser sério.”

Mais uma vez, a exposição às mídias não significa consumo acrítico de notícias e formação de uma opinião bestializada. Ao contrário, a exposição à mídia e a absorção de seu conteúdo ocorrem de forma seletiva, pragmática e, no caso dos batalhadores, em um arco perceptivo que vai da desconfiança à execração.

\subsection{A classe média e a mídia}

A classe média, em seus segmentos médio e médio alto, apresenta grande número de opiniōes sobre a mídia colhidas pelo projeto Radiografia. Seu maior poder aquisitivo permite acesso a mais veículos que a ralé e os batalhadores. Somado a isso, o tempo livre, relativamente maior em relaçáo às outras classes, significa mais exposição à mídia, ou seja, um consumo de informaçôes superior.

A entrevistada 110114, descrevendo sua dieta de informação, ${ }^{8}$ exemplifica uma superexposição à mídia: “jornal, rádio... o rádio, eu já acordo... e a Globo (...) E as redes sociais, né. Eu mexo muito no computador, vejo muita coisa através do computador. E à televisão eu assisto, vejo o jornal, ouço... é assim que eu procuro me manter informada."

Há, contudo, posturas mais seletivas, como a relatada pela entrevistada 114109: "Pra falar a verdade, tem três anos que eu não sei mais o que é novela, jornal, nada”. Portanto, mesmo no segmento de maior exposição midiática, isso não significa necessariamente consumo acrítico de informação. Ao contrário, está presente uma percepção incisiva de que há distorçôes flagrantes nas coberturas jornalísticas. Essa classe coleciona mais exemplos de informaçóes contraditórias que soam estranhas, por serem errôneas, ou mesmo absurdas, por serem deliberadamente distorcidas.

Essas contradições levam a atitudes diferentes, mas complementares. A primeira delas é desconfiar das fontes e valorizar, se não a checagem, pelo menos a pluralidade de informaçóes. Outra atitude é de crítica aberta a tentativas de manipulação. A opção pela pluralidade fica clara na fala do entrevistado 128103.

Cara, geralmente eu leio uma notícia e procuro outra fonte pra ver se aquela notícia está correta. As pessoas que fazem a notícia (...) Então, dizer que um jornalista é completamente isento, que ele não coloca ali a opinião dele, é difícil. (...) Eu procuro (...) ver dois, três jornais na televisão e tentar ler dois ou três periódicos.

O entrevistado 114107 é mais taxativo ao dizer: "Matéria? Tu compra a matéria", indicando que, para uma parcela da classe média, a imprensa perdeu definitivamente a aura de imparcialidade.

8. 0 conceito de dieta de informação remonta a Wurman (1991). 
Na classe média e média alta, a atitude de crítica aberta assume ares de um suposto conhecimento de causa. É uma maneira de se mostrar imune ou pelo menos precavido aos interesses mesquinhos e mal disfarçados que interferem na cobertura jornalística.

Em suma, a classe média não está satisfeita com a mídia que tem à disposição. Os sinais de desencantamento e, em alguns casos, de inconformismo e revolta são evidentes. Por sua maior exposição a esse consumo de informaçóes, o repertório de histórias para contar a esse respeito também é maior e mais ácido.

\section{CONSIDERAÇÕES FINAIS}

Os resultados da pesquisa Radiografia do Brasil Contemporâneo, debruçados sobre as atitudes diante da mídia e dos hábitos de consumo de informação dos brasileiros da ralé, batalhadores e classe média, contrariam frontalmente a tese de Souza (2017) sobre a mídia. Embora não faça referência a ela, o autor parte de pressupostos que são característicos de uma antiga teoria da comunicação, apelidada de teoria da agulha hipodérmica, segundo a qual uma mensagem bombardeada é automaticamente inoculada nas pessoas que a recebem de forma passiva, sem gerar qualquer efeito colateral. A tese já há muito foi testada e refutada por inúmeras pesquisas (Azevedo, 2004). Este artigo se inclui em mais uma dessas refutaçôes.

O cerne do descompasso entre a tese e a observação empírica não está no fato de que a mídia não seja, realmente, um aparato bastante viesado por determinados interesses e tenha um poder assimétrico diante do leitor, ouvinte e telespectador. Essa dominância pode fragilizar a democracia quando é usada para induzir organizaçóes do Estado e setores da opinião pública a comportamentos oportunistas de conluio com uma narrativa midiática que favoreça grupos que disputam espaço na estrutura de poder do país.

Conforme atestado pela pesquisa da organização Repórteres sem Fronteira e do Intervozes, ${ }^{9}$ a mídia no Brasil ostenta o maior número de indicadores de alto risco para a democracia, em uma comparaçáo com outros dez países.

O que os dados compilados indicam, todavia, é que dessa condição da mídia não decorre uma atitude de total passividade, conformismo e bestialização das classes em geral. Não se discute que tais comportamentos possam existir. $\mathrm{O}$ que se póe em dúvida é que eles conformem um padrão. Fosse assim, as classes não teriam clivagens, confrontos e arrependimentos, que de fato são corriqueiros.

As pessoas reagem de forma pragmática e seletiva ao bombardeio de informaçóes e regurgitam, em vez de engolir, muito do que consideram deturpaçóes travestidas de notícia que são oferecidas pela mídia. Ocorrem reaçóes que vão desde o desapontamento com a falta de qualidade da informaçáo oferecida pelo cartel midiático, cansaço com a saturação de determinadas pautas e vieses até críticas contundentes a esses conteúdos. Em alguns casos, verificam-se mesmo situaçôes de boicote a algum veículo de comunicação.

A mídia tradicional se encontra, conforme aponta a Pesquisa Brasileira de Mídia, em franca decadência na sua relação de confiança com o público. O quadro de crise de inúmeros veículos reflete uma mudança acelerada nos hábitos de consumo de informação dos brasileiros, orientada náo apenas por novas tecnologias - em especial, a popularização da internet -, mas também pela própria transformação da maneira como os brasileiros passaram a produzir, reproduzir e reagir às informaçóes. 
Pode-se até aventar a hipótese, que não é objeto deste artigo, de que a oligopolização da mídia nacional, dada a falta de regulação, ao ter produzido um deficit de pluralidade de sua cobertura, de pouco respeito ao contraditório - salvo como formalidade -, e sua tradição de criminalização da política transformaram-se em um feitiço que se voltou contra o próprio feiticeiro.

Uma mídia cujo principal atributo deveria ser sua credibilidade é fustigada por novas formas de comunicaçáo muito mais bombásticas e interativas, que em nada devem ao padrão de programas policiais e de auditório, agora transpostos para o universo da política. Não se pode dizer, no entanto, que o povo assiste a tudo bestializado. O provérbio de Abraham Lincoln que diz que se pode enganar muitos por algum tempo e poucos por muito tempo, mas não a todos por todo o tempo parece uma interpretação mais adequada do que se extrai dos dados do projeto Radiografia.

\section{REFERÊNCIAS}

AZEVEDO, F. A. Agendamento da política. In: RUBIM, A. A. C. (Org.). Comunicação e política: conceitos e abordagens. Salvador: Edufba, 2004.

BRASIL. Secretaria de Comunicação Social da Presidência da República. Pesquisa brasileira de mídia 2014: hábitos de consumo de mídia pela população brasileira. Brasília: Secom, 2014. Disponível em: <https://bit.ly/2RHKSc6>.

- Secretaria de Comunicação Social da Presidência da República. Pesquisa brasileira de mídia 2015: hábitos de consumo de mídia pela população brasileira. Brasília: Secom, 2015. Disponível em: <https://bit.ly/3chUYsa>.

- Secretaria de Comunicação Social da Presidência da República. Pesquisa brasileira de mídia 2016: hábitos de consumo de mídia pela população brasileira. Brasília: Secom, 2016.

SOUZA, J. A elite do atraso: da escravidão à Lava Jato. Rio de Janeiro: Leya, 2017.

WURMAN, R. S. Ansiedade de informaçáo. São Paulo: Cultura Editores Associados, 1991.

\section{BIBLIOGRAFIA COMPLEMENTAR}

ADORNO, T. W. The culture industry: selected essays on mass culture. London: Routledge, 2001. Disponível em: <http://www.imagomundi.com.br/filo/adorno_culture_industry.pdf>.

REPÓRTERES SEM FRONTEIRA; INTERVOZES. Media ownership monitor. [s.1.]: Repórteres sem Fronteira, Intervozes, 2018. Disponível em: <https://brazil.mom-rsf.org/br/destaques/concentracao/>. Acesso em: 19 abr. 2018.

SOUZA, J. A ralé brasileira: quem é e como vive. Belo Horizonte: Editora da UFMG, 2009.

. Os batalhadores brasileiros: nova classe média ou nova classe trabalhadora? 2. ed. Belo Horizonte: Editora da UFMG, 2012.

A tolice da inteligência brasileira: ou como o país se deixa manipular pela elite.

Sáo Paulo: LeYa, 2015. 